Gut, 1973, 14, 767-772

\title{
The abnormal lower oesophageal sphincter in pernicious anaemia ${ }^{1}$
}

\author{
RAYMOND L. FARRELL, OTTO T. NEBEL, ARTHUR T. McGUIRE, ${ }^{2}$ AND \\ DONALD O. CASTELL ${ }^{3}$
}

From the Gastrointestinal Branch, Internal Medicine Service, US Naval Hospital and Gastrointestinal Section, Department of Medicine of the University of Pennsylvania, Philadelphia, Pennsylvania

SUMMARY Lower oesophageal sphincter pressure has been studied in pernicious anaemia patients and controls using an infused open-tipped system. Resting sphincter pressure was significantly $(\mathbf{P}<0.01)$ lower in the pernicious anaemia patients. After gastric acidification with $0 \cdot 1 \mathrm{~N} \mathrm{HCl}$ pressure fell significantly $(P<0.01)$ in both groups. Following subsequent alkalinization, lower oesophageal sphincter pressure for controls rose significantly $(P<0.001)$. For pernicious anaemia patients the pressure after alkali was not greater than resting levels. Graded intravenous doses of pentagastrin in controls resulted in a peak pressure change of $38.5 \pm 4.9 \mathrm{~mm} \mathrm{Hg}$ after the $0.8 \mu \mathrm{g} / \mathrm{kg}$ dose. For patients the peak pressure change was only $13.0 \pm 5.2 \mathrm{~mm} \mathrm{Hg}$ and occurred after 0.4 $\mu \mathrm{g} / \mathrm{kg}$. Cholinergic stimulation with edrophonium $(10 \mathrm{mg})$ produced a peak pressure change of $20.6 \pm 2.6 \mathrm{~mm} \mathrm{Hg}$ in controls but only $3.5 \pm 1.0 \mathrm{~mm} \mathrm{Hg}$ in pernicious anaemia patients $(\mathrm{P}<$ 0.001 ). In addition, no change in lower oesophageal sphincter pressure occurred in patients after stimulation with subcutaneous betazole $(1.5 \mathrm{mg} / \mathrm{kg})$.

In conclusion, the lower oesophageal sphincter in pernicious anaemia is characterized both by a low resting pressure and a decreased response to endogenous and exogenous stimuli. These results suggest a primary end organ defect and most likely indicate abnormal smooth muscle function in pernicious anaemia. Resting sphincter pressure levels and edrophonium response in age-matched subjects indicate that these changes are not due to aging alone.

The lower oesophageal sphincter has been shown to respond to varied hormonal and pharmacological stimuli (Giles, Mason, Humphries, and Clark, 1969; Castell and Harris, 1970; Roling, Farrell, and Castell, 1972; Cohen and Lipshutz, 1971; Bettarello, Tuttle, and Grossman, 1965; Resin, Stern, Sturdevant, and Isenberg, 1972). In particular the hormone gastrin has been shown to cause marked increases in pressure in this sphincter (Giles $e t$ al, 1969; Castell and Harris, 1970) and recent studies indicate that endogenous gastrin is a major determinant of sphincter tone (Lipshutz, Hughes, and Cohen, 1972). The marked elevation of serum gastrin detected in patients with either pernicious anaemia

\footnotetext{
'Presented at the national meeting of the American Federation for Clinical Research in Atlantic City, New Jersey, on 30 April 1972.

'Present address: Arthur T. McGuire, M.D. Genessee Hospital, Rochester, New York

'Please send reprint requests and correspondence to Naval Hospital, Philadelphia, Pennsylvania 19145 (Dr Farrell)

Received for publication 11 June 1973.
}

(Yalow and Berson, 1970) or the Zollinger-Ellison syndrome (Yalow and Berson, 1970) has stimulated interest in lower oesophageal sphincter dynamics in these clinical states. Recent studies of ZollingerEllison patients have documented both the expected high resting lower oesophageal sphincter pressures and a highly significant correlation between mean resting sphincter pressure and fasting serum gastrin levels (Isenberg, Cendes, and Walsh, 1971). The purpose of our study was to record lower oesophageal sphincter pressures in hypergastrinaemic pernicious anaemia patients and to determine the sphincter response of these patients to hormonal and pharmacological stimuli.

\section{Methods}

PATIENTS STUdied

Nine patients receiving maintenance vitamin $B_{12}$ therapy for well documented pernicious anaemia served as the study group. This included six males 
and three females with a mean age of 62 years (range 45 to 74 years). Results of previous studies included a megaloblastic bone marrow, histamine-fast achlorhydria, abnormal Schilling test corrected by exogenous intrinsic factor, low serum vitamin $B_{12}$, and correction of clinical and laboratory abnormalities with parental vitamin $B_{12}$ therapy. Patients with neurological dysfunction were excluded from the study. Fourteen healthy male volunteers with no history of oesophageal dysfunction were used as controls. The mean age of this group was 29 years (range 21 to 42 years). In addition, limited studies were performed on 15 age-matched subjects also without symptoms of oesophageal disease having a mean age of 67 years (range 50 to 82 years).

\section{SERUM GASTRIN DETERMINATION}

The serum gastrin was measured by the double antibody radioimmunoassay technique of McGuigan (1972). Each gastrin determination was done in triplicate. In this laboratory the mean normal fasting gastrin level is $60 \mathrm{pg} / \mathrm{ml}$ with a range up to $200 \mathrm{pg} / \mathrm{ml}^{1}$.

INTRALUMINAL PRESSURE DETERMINATIONS Intraluminal pressures were monitored through a four-channel polyvinyl tube assembly with an outer diameter of $0.5 \mathrm{~cm}$. Three tubes were used to record pressures and were infused with distilled water at a constant rate of $0.6 \mathrm{ml} / \mathrm{minute}$. The fourth channel had multiple perforations over a 7-cm segment and was used to collect gastric secretions. The midpoint of the area of multiple perforations was $15 \mathrm{~cm}$ distal to the point from which lower oesophageal sphincter pressures were recorded. Infused tubes were connected to external transducers and pressures graphed on a multichannel direct-writing recorder. The tubes were arranged so that intraluminal pressures were recorded at three points, $5 \mathrm{~cm}$ apart, through lateral orifices $1.2 \mathrm{~mm}$ in diameter. Mean pressures were recorded as millimetres of mercury using mean fundic pressure as a zero reference. Respiration and swallowing were monitored by belt pneumographs around the chest and larynx.

All studies were performed in the supine position. After an overnight fast the tube assembly was passed into the stomach and slowly withdrawn across the lower oesophageal sphincter until the middle recording orifice was positioned in the sphincter. The assembly was then fastened to the patient's nose so that intraluminal pressures were recorded simultaneously from the distal oesophagus, lower oesophageal sphincter, and gastric fundus. The lower oesophageal sphincter pressure was recorded continuously throughout the study periods. A mean 20- minute basal tracing was recorded for all subjects to determine the resting lower oesophageal sphincter pressure. Statistical significance between mean sphincter pressures was evaluated using Student's t test.

PHYSIOLOGICAL SUPPRESSION AND

STIMULATION OF GASTRIN

These studies were performed on six healthy male volunteers and seven pernicious anaemia patients. After a 20-minute basal period an aliquot of gastric juice was aspirated and the $\mathrm{pH}$ determined directly using a Beckman pH electrode. Hydrochloric acid $(0.1 \mathrm{~N})$ was instilled into the stomach through the distal orifice of the recording tube at a rate of 6 to 10 $\mathrm{ml} / \mathrm{min}$ for a 30-minute period. The stomach was then aspirated through the intragastric collector over a ten-minute period and the $\mathrm{pH}$ of the aspirate determined. In all patients the intragastric $\mathrm{pH}$ was less than $1 \cdot 5$. Sodium bicarbonate $(0 \cdot 1 \mathrm{~N})$ was then instilled into the stomach at a rate of 6 to $10 \mathrm{ml} / \mathrm{min}$ for 30 minutes. Sphincter pressures were monitored throughout the entire study period.

\section{Pentagastrin studies}

Eight control patients and five pernicious anaemia patients were studied after an overnight fast and a 20-minute basal period. Pentagastrin ${ }^{1}$ in a concentration of $50 \mu \mathrm{g} / \mathrm{ml}$ was administered intravenously in doses of $0.025,0.050,0.10,0.20,0.40$, and 0.80 $\mu \mathrm{g} / \mathrm{kg}$, and the pressure response monitored for 10 minutes after each dose. Individual doses were given in random order on separate days.

\section{Smooth muscle stimulants}

Seven normal controls and five pernicious anaemia patients received betazole (Histalog), $1.5 \mathrm{mg} / \mathrm{kg}$, subcutaneously after an overnight fast and a 20minute basal period. Sphincter pressure was monitored for 60 minutes after the injection of Histalog.

On a subsequent day, the effect of edrophonium (Tensilon), $10 \mathrm{mg}$ intravenously, on the sphincter was determined for the seven controls and five pernicious anaemia patients. Pressure was recorded continuously for 10 minutes after injection. In addition, the Tensilon response for nine age-matched subjects was similarly studied.

\section{Results}

Mean basal pressures for control subjects was $17 \cdot 2 \pm$ $0.9 \mathrm{~mm} \mathrm{Hg}( \pm \mathrm{SE})$, and for pernicious anaemia patients was $9.9 \pm 1.4 \mathrm{~mm} \mathrm{Hg}$ (fig 1). These values are significantly different $(\mathrm{P}<0.001)$. The 
mean basal pressure for age-matched subjects was $14.8 \pm 0.9 \mathrm{~mm} \mathrm{Hg}$ which is also significantly different $(P<0.01)$ from the basal pressure of pernicious anaemia patients but not different from the control group.

The effect of acidification and alkalinization on the lower oesophageal sphincter pressure of six controls and seven pernicious anaemia patients is shown in figure 2. With gastric acidification lower oesophageal sphincter pressure decreased significantly $(P<0.01)$ in young controls from a mean basal level of $17.7 \pm 1.6$ to $11.5 \pm 1.8 \mathrm{~mm} \mathrm{Hg}$. For

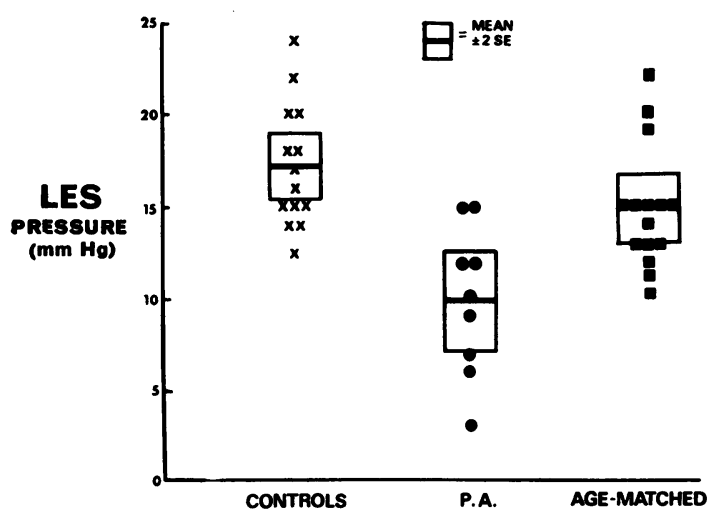

Fig 1 Resting lower oesophageal sphincter (LES) pressure in control patients, pernicious anaemia $(P A)$ patients, and age-matched subjects without oesophageal disease.

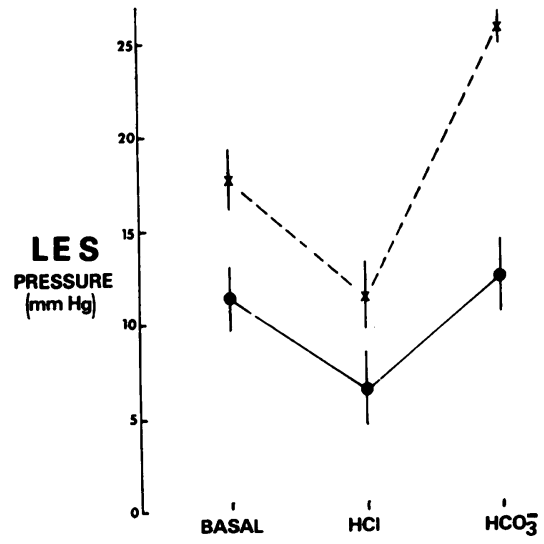

Fig 2 Mean lower oesophageal sphincter (LES) pressure for controls (broken line) and pernicious anaemia patients (solid line) during basal conditions and after gastric acidification $(\mathrm{HCl})$ and alkalinization $\left(\mathrm{HCO}_{3}\right)$. Vertical lines indicate $\pm 1 \mathrm{SE}$ of the mean. the pernicious anaemia patients pressure fell from a basal level of $11.3 \pm 1.7$ to $6.4 \pm 2.1 \mathrm{~mm} \mathrm{Hg}$. The values are also significantly different $(\mathrm{P}<0.01)$. With subsequent alkalinization, lower oesophageal sphincter pressures for controls rose to $25.8 \pm 0.8$ $\mathrm{mm} \mathrm{Hg}$, which was significantly greater than the mean basal level $(P<0.001)$. The lower oesophageal sphincter pressure for the pernicious anaemia group reached a mean of only $12.6 \pm 1.9 \mathrm{~mm} \mathrm{Hg}$ after alkali, which was not significantly different from the mean basal pressure.

The lower oesophageal sphincter pressure response to intravenous pentagastrin for control subjects and pernicious anaemia patients is shown in figure 3 . The response of the pernicious anaemia group was attenuated when compared to that shown by control subjects, especially at higher dose levels. The pressure response for pernicious anaemia patients was significantly greater than basal pressures only at the $0.2 \mu \mathrm{g} / \mathrm{kg}(\mathrm{P}<0.02), 0.4 \mu \mathrm{g} / \mathrm{kg}(\mathrm{P}<0.05)$, and 0.8 $\mu \mathrm{g} / \mathrm{kg}(\mathrm{P}<0.05)$ dose. The peak pressure change was only $13.0 \pm 5.2 \mathrm{~mm} \mathrm{Hg}$, and occurred with $0.4 \mu \mathrm{g} / \mathrm{kg}$ of pentagastrin. This represented a change of only $113 \%$ from a mean basal pressure of $11.7 \pm 1.0 \mathrm{~mm}$ Hg.

By contrast, pressure changes for the control subjects were significant $(\mathrm{P}<0.01)$ at all pentagastrin doses. The maximal change of $38.5 \pm 4.9 \mathrm{~mm} \mathrm{Hg}$ occurred after $0.8 \mu \mathrm{g} / \mathrm{kg}$ and represented a change of $229 \%$ from a mean basal pressure of $16.8 \pm 1 \cdot 1$ $\mathrm{mm} \mathrm{Hg}$. The pressure response for controls was significantly greater than that shown by the pernicious anaemia patients with both the $0.4 \mu \mathrm{g} / \mathrm{kg}(\mathrm{P}<0.05)$ and $0.8 \mu \mathrm{g} / \mathrm{kg}(\mathrm{P}<0.01)$ dose.

The effect of a subcutaneous injection of $1.5 \mathrm{mg} / \mathrm{kg}$

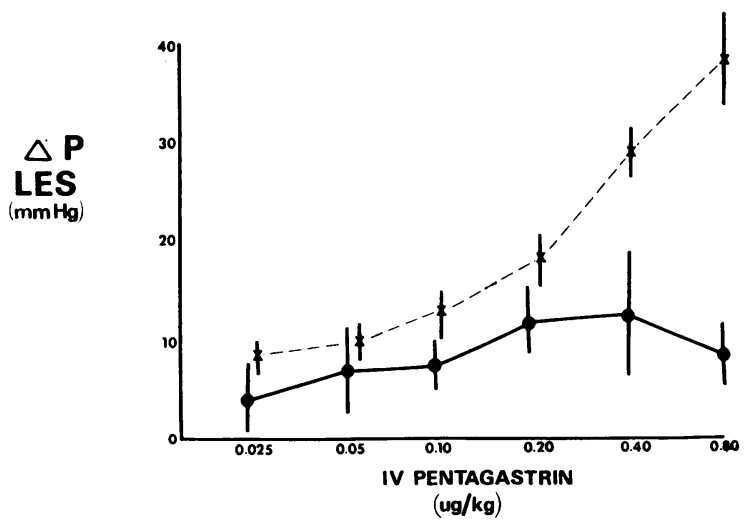

Fig 3 Lower oesophageal sphincter (LES) pressure response $(\triangle P)$ to graded doses of intravenous pentagastrin in pernicious anaemia patients (solid line) and control subjects (broken line). Vertical lines indicate $\pm 1 S E$ of the mean. 
of Histalog on lower oesophageal sphincter pressure is shown in figure 4. The sphincter pressure of the control group rose significantly $(P<0.01)$ from a basal level of $15.6 \pm 1.7 \mathrm{~mm} \mathrm{Hg}$ and reached a peak pressure of $26.1 \pm 1.5 \mathrm{~mm} \mathrm{Hg}$ at 30 minutes after injection. The pressure remained elevated throughout the remainder of the 60 -minute period. From a basal pressure of $10.6 \pm 2.1 \mathrm{~mm} \mathrm{Hg}$ the pernicious anaemia group showed no significant change in pressure for a full 60 minutes after Histalog injection.

Figure 5 illustrates the lower oesophageal sphincter pressure response in controls, pernicious anaemia patients, and age-matched subjects to the intravenous administration of $10 \mathrm{mg}$ of Tensilon given over a one-minute period. Within six minutes after injection

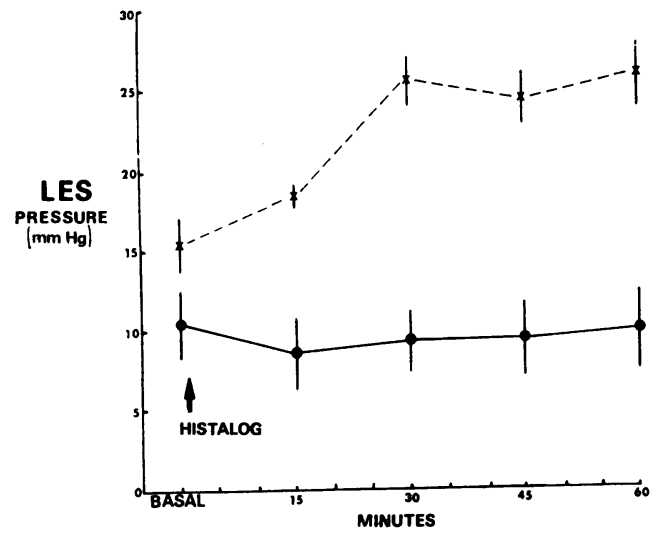

Fig 4 Lower oesophageal sphincter (LES) pressure for 60 minutes after $1.5 \mathrm{mg} / \mathrm{kg}$ subcutaneous Histalog in controls (broken line) and pernicious anaemia patients (solid line). Vertical lines indicate $\pm 1 S E$ of the mean.

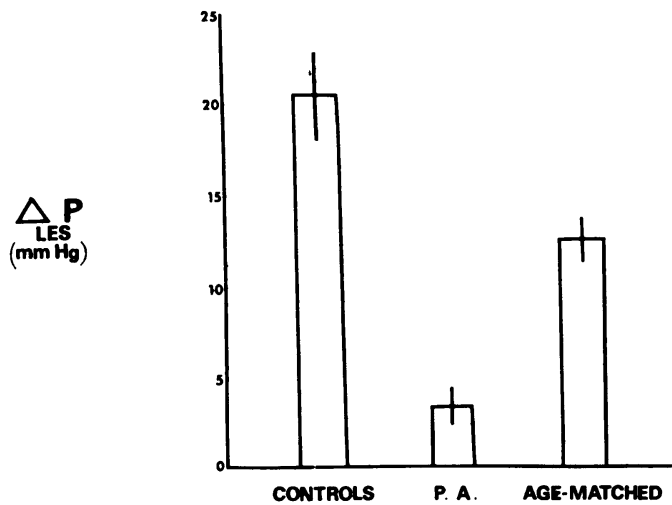

Fig 5 Mean lower oesophageal sphincter (LES) pressure change $(\triangle P)$ to $10 \mathrm{mg}$ Tensilon intravenously in controls, pernicious anaemia $(P A)$ patients, and age-matched subjects. Vertical lines indicate $\pm 1 S E$ of the mean. a pressure increase of $20.6 \pm 2.6 \mathrm{~mm} \mathrm{Hg}$ occurred in control subjects. The peak pressure of $36.0 \pm 4.4$ $\mathrm{mm} \mathrm{Hg}$ was significantly greater $(\mathrm{P}<0.001)$ than the mean basal pressure of $15.4 \pm 1.9 \mathrm{~mm} \mathrm{Hg}$. For the pernicious anaemia patients a peak pressure change of only $3.5 \pm 1.0 \mathrm{~mm} \mathrm{Hg}$ occurred, which was not significantly greater than the mean basal pressure of $11.0 \pm 1.7 \mathrm{~mm} \mathrm{Hg}$. In contrast, sphincter pressure for age-matched subjects increased 12.3 \pm $1.2 \mathrm{~mm} \mathrm{Hg}$ after Tensilon. Peak pressure was significantly greater $(P<0.001)$ than mean basal pressure.

\section{SERUM GASTRIN}

Mean fasting serum gastrin for the pernicious anaemia patients was $1298 \pm 334 \mathrm{pg} / \mathrm{ml}$. There was a poor correlation $(r=0.43)$ between resting lower oesophageal sphincter pressure and fasting serum gastrin levels in these patients.

\section{Discussion}

In 1969 the stimulatory effect of exogenous pentagastrin on the lower oesophageal sphincter was first demonstrated (Giles et al, 1969; Castell and Harris, 1970). Subsequent studies have documented the importance of endogenous gastrin in regulating pressure in this sphincter (Castell and Levine, 1971) and observations in vitro using isolated lower oesophageal smooth muscle of the oppossum suggest that gastrin is a major determinant of lower oesophageal sphincter tone (Lipshutz et al, 1972). Thus recent reports of high sphincter pressures in ZollingerEllison patients having marked elevations of circulating gastrin would seem consistent with current concepts of lower oesophageal sphincter dynamics (Isenberg et al, 1971). However, in contrast to the Zollinger-Ellison patients, preliminary studies in hypergastrinaemic pernicious anaemia patients revealed that mean sphincter pressure was not significantly greater than normogastrinaemic controls (Isenberg et al, 1971). The hypergastrinaemic pernicious anaemia patients in our study had resting lower oesophageal sphincter pressures significantly lower than either age-matched subjects without oesophageal dysfunction or normal controls. Our observations on pernicious anaemia patients differ dramatically from previously reported ZollingerEllison patients with equivalent elevations of serum gastrin (Isenberg et al, 1971). Furthermore, our studies indicate that low sphincter pressure in the pernicious anaemia group is not a consequence of age per se in view of the significantly greater mean resting pressure in the age-matched group.

Lower oesophageal sphincter pressure has been shown to decrease and increase after apparent 
endogenous gastrin suppression and stimulation secondary to gastric acidification and alkalinization (Castell and Harris, 1970; Castell and Levine, 1971). Subsequently it has been shown that a decrease in serum gastrin occurs after antral acidification and a rise in gastrin follows antral alkalinization (Yalow and Berson, 1970; Hansky, Korman, Cowley, and Baron, 1971). The significant decrease in sphincter pressures seen in our pernicious anaemia patients and controls after gastric acidification would seem consistent with an intact physiological suppression of the gastrin-secreting cells in both groups. On the other hand, the failure of alkalinization to elevate lower oesophageal sphincter pressure significantly in the pernicious anaemia patients contrasts with the response of the control group. Recent observations have shown that serum gastrin levels in pernicious anaemia patients as in controls increase after a test meal (Berson, Walsh, and Yalow, in press). Thus pernicious anaemia patients appear able to release endogenous gastrin in response to a physiological stimulus. Therefore, the failure of lower oesophageal sphincter pressure to increase after alkalinization in our patients would appear to represent an abnormal response to endogenous gastrin stimulation.

Further analysis of the dose-response relationship of the pernicious anaemia sphincter to pentagastrin seems to help to clarify the abnormality present in these patients. In the pernicious anaemia group a peak pressure change of only $13.0 \mathrm{~mm} \mathrm{Hg}(113 \%)$ was obtained as compared to a peak change of 38.5 $\mathrm{mm} \mathrm{Hg}(229 \%)$ in the control group. The response of the pernicious anaemia patients was attenuated when compared with control subjects at all dose levels with the greatest difference evident at higher doses.

Could an intrinsic defect in the end organ itself explain the abnormal response to exogenous pentagastrin and endogenous gastrin stimulation as well as low resting sphincter pressures in our hypergastrinaemic pernicious anaemia patients? If the lower oesophageal sphincter smooth muscle was defective one would expect it to respond abnormally to pharmacological and hormonal stimuli acting either directly on the smooth muscle or indirectly through the release of neurotransmitters.

Gastrin has been shown by Lipshutz and Cohen (1971) to act on the lower oesophageal sphincter as an 'indirect'-stimulant. Using in-vitro preparations of oppossum lower oesophageal sphincter muscle these investigators were able to block the stimulatory effect of gastrin with tetrodotoxin, an antagonist to neural transmission. Similar concentrations of tetrodotoxin failed to block the stimulatory effect of acetylcholine on lower oesophageal sphincter smooth muscle (Lipshutz and Cohen, 1971). Thus, acetylcholine would appear to act as a more 'direct' smooth muscle stimulant. Likewise, cholinesterase inhibitors directly stimulate smooth muscle through potentiation of the effect of available acetylcholine released at cholinergic nerve terminals. The abnormal response of the pernicious anaemia sphincter to gastrin could be due to an abnormality at the postganglionic neurone or any distal site. The inability of Tensilon to elicit a response in sphincter pressure in these patients although more suggestive of abnormal muscle function, could also be explained by defective formation of available acetylcholine at postganglionic endings.

The failure of Histalog to increase sphincter pressure in our pernicious anaemia patients is of particular interest. In normal subjects Histalog has been shown to stimulate the lower oesophageal sphincter despite its gastric acid stimulatory capacity. Castell and Harris (1970) noted the paradoxical rise in sphincter pressure in normal subjects in the presence of enhanced acid secretion and presumed suppression of endogenous gastrin release. Those authors speculated that the phenomena occurred as a consequence of either Histalog-mediated gastrin release or a direct effect of Histalog on the sphincteric smooth muscle. When Histalog stimulation failed to increase lower oesophageal sphincter pressure in preliminary studies on pernicous anaemia patients, the authors discounted a direct effect, suggesting instead that the then presumed deficit of endogenous gastrin in pernicious anaemia best explained the abnormal response. However, in the light of current knowledge of gastrin dynamics in pernicious anaemia as well as the known stimulatory effect of histamine on gastric smooth muscle (Paton and Vane, 1963) a direct effect of Histalog on the lower oesophageal sphincter smooth muscle would seem the best explanation of our data in both pernicious anaemia patients and controls.

The inability of either Histalog, acting as a direct muscle stimulant, or Tensilon, acting through acetylcholine to raise lower oesophageal sphincter pressure, seems best explained by an abnormality in the smooth muscle itself in pernicious anaemia. Likewise, indirect stimulators of lower oesophageal sphincter smooth muscle such as gastrin would also effect a poor response in the presence of a smooth muscle defect. Although one could postulate that end organ fatigue might occur as a consequence of prolonged stimulation of the sphincter by elevated serum gastrin, the recent observations of high lower oesophageal sphincter pressure in Zollinger-Ellison patients tend to refute this possibility (Isenberg et al, 1971). Alternatively, it seems that such a smooth muscle defect might be merely a consequence of aging. Although the effect of aging on the lower oesophageal sphincter is uncertain, the normal resting 
lower oesophageal sphincter pressures and significant sphincter response to smooth muscle stimulation with Tensilon in our age-matched group tend to refute the possibility that the abnormal sphincter dynamics of pernicious anaemia represents a manifestation of ageing.

The possibility of smooth muscle failure in the gastrointestinal tract of pernicious anaemia is not unpredicted. Anatomical studies in 1938 revealed smooth muscle atrophy without fibrosis in necropsy studies of the stomach of pernicious anaemia patients (Magnus and Ungley, 1938). Although histologic studies of the oesophagus and oesophagogastric junction in pernicious anaemia have not been reported, the results of our investigations on lower oesophageal sphincter function in patients with this disease suggest the conclusion that a defect in lower oesophageal smooth muscle is present in this disease.

The opinions expressed herein are those of the authors and cannot be construed as reflecting the views of the Navy Department or of the naval service at large.

\section{References}

Bettarello, A., Tuttle, S. G., and Grossman, I. (1965). Effects of autonomic drugs on gastroesophageal reflux. Gastroenterology, 39, 340-346.

Berson, S. A., Walsh, J. H., and Yalow, R. (1973). Radioimmunoassay of gastrin in human plasma and regulation of gastrin secretion. In Symposium on Frontiers in Gastrointestinal Hormone Research, Uppsala.

Castell. D. O., and Harris, L. D. (1970). Hormonal control of gastroesophageal-sphincter strength. New Engl. J. Med., 282, 886-889.

Castell, D. O., and Levine, S. M. (1971). Lower oesophageal sphincter response to gastric alkalinization. Ann. intern. Med., 74, 223227.

Cohen, S., and Lipshutz, W. (1971). Hormonal regulation of human lower oesophageal-sphincter competence: interaction of gastrin and secretin. J. clin. Invest., 50, 449-454.

Giles, G. R., Mason, M. C., Humphries, C., and Clark, C. G. (1969). Action of gastrin on the lower oesophageal sphincter in man. Gut, 10, 730-734.

Hansky, J., Korman, M. G., Cowley, D. J., and Baron, J. H. (1971). Serum gastrin in duodenal ulcer. II. Effect of insulin hypoglycaemia. Gut, 12, 959-968.

Isenberg, J., Cendes, A., and Walsh, J. H. (1971). Resting and pentagastrin stimulated gastroesophageal sphincter pressure in patients with Zollinger-Ellison syndrome. Gastroenterology, 61, 655-659.

Lipshutz, W., Hughes, W., and Cohen, S. (1972). The genesis of lower esophageal sphincter pressure: its identification through the use of gastrin antiserum. J. clin. Invest., 51, 522-529.

Lipshutz, W., Tuch, A. F., and Cohen, S. (1971). A comparison of the site of action of gastrin I on lower esophageal sphincter and antral circular muscle. Gastroenterology, 61, 454-460.

Magnus, H. A., and Ungley, C. C. (1938). The gastric lesion of pernicious anaemia. Lancet, 1, 420-423.

McGuigan, J. E. (1968). Immunochemical studies with synthetic human gastrin. Gastroenterology, 54, 1005-1011.

Paton, W. D. M., and Vane, J. R. (1963). An analysis of the response of the isolated stomach to electrical stimulation and to drugs. J. Physiol. (Lond.), 165, 10-46.

Resin, H., Stern, D. H., Sturdevant, R. A., and Isenberg, J. I. (1972). Effect of octapeptide of cholecystokinin on lower esophageal sphincter pressure in man. Gastroenterology, 62, 797.

Roling, G. T., Farrell, R. L., and Castell, D. O. (1972). Cholinergic response of the lower esophageal sphincter. Amer. J. Physiol., 222, 967-972.

Yalow, R., and Berson, S. A. (1970). Radioimmunoassay of gastrin. Gastroenterology, 58, 1-14. 